\title{
O PROJETO “HISTÓRIA ORAL DO SUPREMO” DA FGV DIREITO RIO
}

\section{FGV DIREITO RIO'S PROJECT “ORAL HISTORY OF THE BRAZILIAN SUPREME COURT"}

PEDRO CANTISANO ${ }^{1}$

\begin{abstract}
Resumo: O projeto "História Oral do Supremo (1988-2013)" foi liderado pela Escola de Direito da Fundação Getúlio Vargas do Rio de Janeiro (FGV Direito Rio), com participação do Centro de Pesquisa e Documentação de História Contemporânea CPDOC e da FGV Direito SP. O objetivo do projeto foi criar um registro audiovisual e escrito da história do Supremo Tribunal Federal a partir de depoimentos de ministros aposentados e em atividade. Todas as entrevistas realizadas estão disponíveis online em formato open access no site historiaoraldosupremo.fgv.br. Neste artigo, apresento em linhas gerais as origens do projeto no contexto da recepção da História Oral no Brasil, as fases de realização do projeto, seus desafios metodológicos e seu impacto dentro e fora da academia. Para além de produzir conteúdo biográfico, o projeto fornece material rico para pesquisas sobre a história e o funcionamento do STF. Para além de fonte de pesquisa, o projeto é parte de um esforço de democratização do conhecimento sobre esta instituição.
\end{abstract}

Palavras-Chave: Pesquisa jurídica; Supremo Tribunal Federal; História Oral.

ABSTRACT: The project "Oral History of the Brazilian Supreme Court (1988-2013)" was led by the Fundação Getúlio Vargas Law School in Rio de Janeiro (FGV Direito Rio), in collaboration with the Center for Research and Documentation in Contemporary History (CPDOC) and the FGV Law School in São Paulo. Its objective

${ }^{1}$ LLM, MA e PhD, University of Michigan. Este ensaio foi escrito enquanto era coordenador do projeto "História Oral do Supremo", na Escola de Direito da Fundação Getúlio Vargas do Rio de Janeiro (FGV Direito Rio), em 2016. O ensaio contém reflexões pessoais do autor que, de nenhuma forma, refletem posições institucionais da FGV Direito Rio. Atualmente, é Visiting Assistant Professor da Kenyon College (EUA). E-mail: pjimenez@umich.edu. 
was to produce an audiovisual and written register of the Supreme Court's history based on interviews with former and current Supreme Court justices. All interviews are available online in open access format at historiaoraldosupremo.fgv.br. In this article, I introduce the project's origins in the context of the reception of Oral History in Brazil, the project's phases, its methodological challenges, and its impact inside and outside academia. Beyond biographical content, the project offers rich research material for the history and functioning of the Supreme Court. In addition to being a research source, the project is part of an effort to democratize knowledge about this institution.

KEYWORDS: Legal research; Brazilian Supreme Court; Oral History.

\section{INTRODUÇÃO}

"História Oral do Supremo (1988-2013)" é um projeto liderado pela Escola de Direito da Fundação Getúlio Vargas do Rio de Janeiro (FGV Direito Rio), com participação do Centro de Pesquisa e Documentação de História Contemporânea CPDOC e da FGV Direito SP. O objetivo do projeto é criar um registro audiovisual e escrito da história do Supremo Tribunal Federal a partir de depoimentos de ministros aposentados e em atividade. Até o final de 2016, o projeto planejava ter publicado e disponibilizado em seu banco de dados online, 15 destes depoimentos. Esperava-se que, no total, ao menos 23 ministros e ex-ministros fariam parte do produto final. ${ }^{2}$ Deste modo, o projeto se constitui como fonte inédita para historiadores, cientistas políticos, cientistas sociais, pesquisadores do direito e jornalistas, entre outros, interessados no passado e no presente do tribunal.

O projeto é constituído por três etapas abrangentes: a pesquisa e elaboração de roteiros, a realização e produção de entrevistas e a difusão. Neste artigo, discorrerei sobre cada uma destas etapas. Antes, porém, cumpre uma breve introdução sobre a História Oral e sua recepção no Brasil. Na conclusão, darei ênfase ao potencial da História Oral para a pesquisa em direito e ao papel do "História Oral do Supremo" no projeto científico e didático inovador da FGV Direito Rio.

\section{O QUE É HISTÓRIA ORAL?}

A História Oral é um método-técnica de pesquisa baseado em entrevistas gravadas com atores participantes do processo histórico. Tem como objetivo acessar versões da história a partir das perspectivas individuais destes atores. O método pode dar ênfase a trajetórias de vida ou a entrevistas temáticas. A primeira costuma produzir

2 O projeto foi concluído com 21 entrevistas, todas disponíveis em open access no site http://historiaoraldosupremo.fgv.br/ 
entrevistas mais longas, em que a biografia do entrevistado é o fio condutor da narrativa histórica. As entrevistas temáticas, por sua vez, costumam ser menores, focadas na perspectiva do(a) entrevistado(a) sobre determinados acontecimentos e instituições, sem, no entanto, deixar de produzir, também, material biográfico. É possível, ainda, que seja feita uma mistura entre as duas ênfases, como no caso do projeto "História Oral do Supremo".

Quando o método é aplicado a diversos atores participantes de uma mesma instituição, a coletânea de entrevistas fornece uma versão da memória coletiva da instituição - no projeto em análise, do Supremo Tribunal Federal. A História Oral também produz conteúdo biográfico, que, quando reunido, torna-se biografia coletiva de um determinado grupo social - no caso, do grupo de ministros e ex-ministros do Supremo, fração de um conjunto mais abrangente de membros das elites jurídicas nacionais. ${ }^{3}$

A História Oral teve origem nos Estados Unidos, nas décadas de 1940 e 1950, após a invenção do gravador. Em 1948, o jornalista Allan Nevins criou o Columbia Center for Oral History, no âmbito da Columbia University, em Nova Iorque. Hoje, este projeto pioneiro conta com mais de dez mil entrevistas. ${ }^{4} \mathrm{O}$ método se desenvolveu durante as décadas de 1960 e 1970, especialmente como um caminho para se contar a história dos excluídos, ou seja, daqueles que não produziram os documentos escritos e oficiais. A História Oral teve, portanto, papel fundamental na revisão historiográfica que pretendia uma "história vista de baixo", contra a "história vista de cima", dos vencedores. ${ }^{5}$ Em 1975, depois que especialistas estadunidenses e mexicanos deram um curso na Fundação Getúlio Vargas, foram instituídos os primeiros programas brasileiros de História Oral, na própria FGV, com o CPDOC, e na Universidade Federal de Santa Catarina. Durante as décadas de 1980 e 1990, principalmente com a revitalização do interesse pela história política do país após a redemocratização, programas semelhantes se espalharam pelo Brasil. ${ }^{6}$

Apesar de ter sido recebida com desconfiança entre os historiadores, a História Oral se consolidou como método, em revistas especializadas, conferências e programas de pós-graduação pelo mundo. ${ }^{7} \mathrm{O}$ que, inicialmente, foi tido como fonte não confiável, inferior às fontes escritas, hoje é visto como fonte histórica que, assim como todas as outras, possui peculiaridades que devem ser levadas em consideração pelo historiador. Diferentemente de um documento escrito produzido à época dos acontecimentos, a entrevista de História Oral é produzida no presente, em uma

${ }^{3}$ Referência para a História Oral no Brasil é ALBERTI, Verena. Manual de História Oral. Rio de Janeiro: FGV, 2013. Para observações específicas sobre o projeto "História Oral do Supremo", Fernando Fontainha, que coordenou o projeto entre 2013 e 2015, produziu o position paper "O Supremo por seus ministros: a história oral do STF nos 25 anos da Constituição (1988-2013)".

4 A base de dados do Columbia Center for Oral History pode ser acessada em http://library.columbia.edu/find/oral-history-portal.html

5 TREBITSCH, Michel. História Oral no discurso da História Contemporânea. In: FERREIRA, Marieta de Moraes (org.). História Oral e Multidisciplinariedade. Rio de Janeiro: Diadorim Editora Ltda., 1994, p. 21.

${ }^{6}$ FERREIRA, Marieta de Moraes. Oral history in Brazil: an assessment. Rio de Janeiro: CPDOC, 2004.

7 Para os interessados em se aprofundar a respeito do método, ver www.oralhistory.org - site da Oral History Association, que contém link para a Oral History Review.

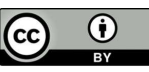


interação entre historiador e sujeito da história. Portanto, deve ser lida como um produto dos acontecimentos narrados, da trajetória do entrevistado e do momento em que a entrevista foi realizada. Ou seja, a entrevista é uma versão do passado a partir da memória presente do entrevistado, reconstruída no diálogo com o entrevistador. Isto significa que analisar os depoimentos requer atenção às lacunas e às seleções, conscientes e inconscientes, que perpassam esta memória. Em estudos aprofundados sobre instituições, como o Supremo Tribunal Federal, ou acontecimentos, como, por exemplo, a Assembleia Nacional Constituinte de 1987-1988, os pesquisadores devem ler as entrevistas em confronto umas com as outras e com outras fontes, escritas e visuais. Diferentes fontes podem corroborar versões ou mostrar que existem divergências a respeito da história que se pretende acessar.

Hoje, o CPDOC abriga um banco de dados com mais de duas mil entrevistas com atores participantes da história brasileira desde a década de 1930, disponíveis online. ${ }^{8}$ O gravador foi substituído por câmeras de vídeo, que registram as entrevistas em formatos que podem ser armazenados e consultados. A FGV Direito Rio, por sua vez, lidera projetos de História Oral, em conjunto com o CPDOC, focados nas instituições do direito brasileiro. Os dois projetos de referência, atualmente, são o projeto "História Oral do Supremo" e o projeto "Construindo um judiciário responsivo: uma análise da atuação do Conselho Nacional de Justiça", que realizou entrevistas temáticas com conselheiros do CNJ.

\section{ETAPAS DE REALIZAÇão do “HistóRIa ORAL do SUPREMO”}

\section{Pesquisa e elaboração de roteiros}

Após uma fase preliminar de treinamento da equipe, coordenada por Fernando Fontainha e Nelson Jobim e formada por professores, pesquisadores e estagiários da Direito Rio, CPDOC e Direito SP, passou-se à fase de pesquisa para elaboração de roteiros. O projeto iniciou-se com o objetivo de entrevistar todos os ministros e ministras aposentado(a)s e em atividade, que foram divididos entre as equipes das três unidades participantes, encarregadas de elaborar os roteiros e de realizar as entrevistas.

As perguntas que informaram a elaboração dos roteiros e que estruturariam as entrevistas podem ser divididas em três grandes grupos: $\left(1^{\circ}\right)$ Trajetória; $\left(2^{\circ}\right)$ Cotidiano do Supremo; e ( $\left.3^{\circ}\right)$ Hard cases. As perguntas, elencadas abaixo, se encaixam entre as duas ênfases possíveis em entrevistas de História Oral. Ou seja, recuperam tanto as trajetórias de vida do(a)s ministro(a)s, quanto temas específicos sobre o dia-a-dia e os casos mais importantes decididos pelo Supremo Tribunal Federal. Sua elaboração teve por objetivo dar unidade ao corpo de entrevistas, para que fossem produzidas diferentes perspectivas sobre os mesmos temas.

$\left(1^{\mathrm{o}}\right)$ Trajetória

Quais são as trajetórias que tornam alguém "supremável"?

${ }^{8}$ Disponível em: <http://cpdoc.fgv.br/acervo/historiaoral>. 
Quando se começa a trabalhar objetivamente para chegar ao STF?

Como se passa o processo de escolha e indicação pelo presidente?

Como se passa a sabatina no Senado? Ela é mesmo pro forma?

Como um ministro "novato" é recebido no STF?

$\left(2^{\circ}\right)$. Cotidiano do Supremo

Como é a rotina de trabalho de um ministro do STF?

Como interagem e/ou competem os ministros entre si?

Como é o convívio com demais atores internos (assessores, funcionários...)?

Como é o convívio com demais atores externos (advogados, políticos, imprensa...)?

Qual foi o impacto da instituição da transmissão televisiva das sessões?

\section{$\left(3^{\circ}\right)$. Hard cases}

Como um determinado caso se torna um hard case?

Como surgem consensos na separação do trabalho "ordinário" do "relevante"?

Quais atores externos influem na construção de um hard case (imprensa, políticos...)?

Como se compõem coalizões e se resolvem divergências no julgamento dos hard cases?

Para a elaboração dos roteiros, os pesquisadores realizaram extensa pesquisa documental, focada primordialmente nas seguintes fontes escritas: jornais, revistas, sites, currículo lattes, jurisprudência do Supremo e perfil institucional. Como resultado, foram produzidos roteiros individuais para todos os ministros e ministras aposentado(a)s e em atividade. Para exemplificar, abaixo está parte do roteiro (editado), elaborado por Leonardo Sato e Luciana Frattini, para a entrevista com o ministro Nelson Jobim:

\section{MINISTRO NELSON JOBIM}
ANO
EVENTOS

1946 Nascimento. Santa Maria, RS. Filho de Hélvio Jobim e Namy Azevedo Jobim. Irmãos: Walter Jobim Neto (formado em direito) e Helvio Jobim Filho (formado em engenharia). Hélvio Jobim (1918-2005) foi advogado e deputado estadual no RS pelo PSD, 1959-1963. Presidente municipal do PSD em Santa Maria.

Neto de Válter Jobim (1892-1974), advogado e político no RS desde 1920, deputado federal pelo RS em 1935, governador do estado de 1947-1951 pelo PSD com apoio de Vargas, embaixador do Brasil no Uruguai de 1951-1954. Participou das revoluções/revoltas de 1923, 1930, 1932. Filiara-se ao Partido Libertador em 1928. Secretário de Obras Públicas do governo Vargas, de 1937-1939. Presidente do Partido Libertador em 1937. Filiado ao Partido Social Democrático em 1945.

1964 Ingressa na UFRGS - Ciências Jurídicas e Sociais (1964-1968). 
1968 Bacharel em Ciências Jurídicas e Sociais - UFRGS (1964-1968).

1969 Início da Advocacia em Santa Maria, RS (1969-1994).

1974 Condecoração Poder Judiciário: Mérito Judiciário, Tribunal de Justiça, 1974.

1977 Presidente da Subseção da OAB Santa Maria/RS (1977-1978). Início.

- Participação na 1ํㅗㄹ Semana Jurídica de São Gabriel, 16 a 20 de setembro de 1977.

1985 Vice-Presidente da OAB, Seção Rio Grande do Sul (1985-1986). Início.

Situado entre a oposição ao regime militar, devido à defesa do habeas-corpus e do direito de defesa dos presos políticos.

1986 Vice-Presidente da OAB, Seção Rio Grande do Sul (1985-1986). Fim.

Professor na Escola Superior do Ministério Público da Associação do Ministério Público do Rio Grande do Sul. Fim.

- Professor da Escola Superior de Magistratura da Associação dos Juízes do Rio Grande do Sul, lecionando Direito Processual Civil, Introdução ao Direito e Filosofia do Direito (19801986). Fim.

- Diploma de Cidadania por participar da campanha da Constituinte 86.

- Eleito Deputado Federal Constituinte pelo PMDB/RS (1987-1991). Defensor da

Constituinte Exclusiva, ao invés da Constituinte Congressual então adotada.

- Proposta "de proteger os trabalhos constitucionais de constrangimentos impostos por dispositivos da Constituição de 1967, ainda em vigor, como os que tratavam das medidas de emergência e do estado de sítio, ou da edição de decretos-lei por parte do Executivo. No seu entendimento, a Constituinte teria, como "poder originário", competência para estabelecer normas reguladoras do processo de transição democrática".

"Visava a restringir ao máximo o exercício da função legislativa pelo presidente da República e impedir o voto dos senadores eleitos em 1982. Discutida e aceita pelos setores "progressistas" do PMDB, a proposta motivou um dos primeiros confrontos do partido com o governo Sarney. A pressão do Executivo e dos setores conservadores de dentro e de fora do PMDB fez, no entanto, com que o partido voltasse atrás na aceitação da proposta, que, para Jobim, tiraria a Constituinte "dos trilhos da conciliação com as elites"." - Fonte: CPDOC

1987 Deputado Federal pelo Rio Grande do Sul (1987-1991). Início.

Deputado na Assembleia Nacional Constituinte:

- Relator-Substituto na elaboração do Regimento Interno da ANC; Suplente da

Subcomissão do Poder Legislativo;

- Suplente da Comissão de Organização dos Poderes e Sistema de Governo;

- Membro titular da Comissão de Sistematização;

- Membro titular da Comissão de Redação;

- Relator-Adjunto da Comissão de Sistematização.

Um dos Vice-Líderes do PMDB: "Sua inserção no grupo conhecido como "histórico" ou "autêntico" do PMDB, composto pelas lideranças remanescentes do MDB, fora tão bem- 
sucedida que foi logo convidado pelo líder do partido na Constituinte, deputado Mário Covas, a assumir uma das vice-lideranças da agremiação." - Fonte: CPDOC

Participação no V Congresso Latino-Americano de Magistrados, em Porto Alegre, 24 de abril de 1987.

1988 Líder do PMDB na Constituinte, devido à fundação do PSDB (06/1988, por FHC, e o próprio Mário Covas). Cargo disputado com Ibsen Pinheiro, então líder do partido na Câmara.

Administrou a divisão da bancada e a oposição de Sarney ao projeto de constituição do PMDB, que, segundo o presidente, esvaziava as funções do Executivo com o deslocamento de parte de seus poderes para o Congresso e o Judiciário. - Fonte: CPDOC $\mathrm{Na}$ Constituinte: Nacionalista, mas contra as propostas estatizantes.

Votou CONTRA: presidencialismo, mandato de 5 anos para Sarney, a limitação dos juros reais em $12 \%$ ao ano, a jornada semanal de 40 horas, a criação de um fundo de apoio à reforma agrária, a limitação do direito de propriedade produtiva, a estabilidade no emprego, a estatização do sistema financeiro, a adoção da pena de morte e a legalização do jogo do bicho.

Votou A FAVOR: soberania popular, ao rompimento de relações diplomáticas com países de orientação racista, à legalização do aborto, ao mandado de segurança coletivo, ao turno ininterrupto de seis horas de trabalho, ao aviso prévio proporcional, à manutenção da unicidade sindical, à instituição do voto facultativo aos 16 anos, à nacionalização do subsolo, à proibição do comércio de sangue, à limitação dos encargos da dívida externa, à anistia aos micro e pequenos empresários e à desapropriação da propriedade produtiva. - JOBIM, Nelson. "Penas Alternativas: Pontos para Reflexão". In: Hermenêutica e Aplicação do Direito, Ed. Forense, 10ª edição, 1988, p. 40.

- JOBIM, Nelson. Atuação na constituinte. Brasília: Câmara dos Deputados, Coordenação de Publicações, 1988. 55 p.

1988 -Poder constituinte originário e poder constituinte derivado: discurso pronunciado na Sessão de 3-3-88, pelo Deputado Constituinte Nelson Jobim, como Líder do PMDB. Brasília: Câmara dos Deputados, Coordenação de Publicações, 1988. p. 3-8.

-Medalha: Brigada Militar 150 anos, 2 de outubro de 1988.

-Defensor da Liberdade e da Justiça Social, Prefeitura Municipal de Cuiabá, outubro de 1988.

- Homenagem dos Advogados de Goiás, Anápolis, 22 de outubro de 1988, Felicíssimo José de Sena, Presidente da OAB - GO.

A partir de roteiros como este, os entrevistadores podem elaborar estratégias de perguntas para as entrevistas. Entretanto, os roteiros em si já são materiais ricos em informações para pesquisas sobre as elites jurídicas do país. No roteiro acima, por exemplo, podemos perceber a circulação do ministro Jobim, em diferentes graus de proximidade, por meios como universidades, judiciário, a Ordem dos Advogados do Brasil, as Forças Armadas e partidos políticos, além de sua participação central durante 
a Assembleia Nacional Constituinte de 1987-1988. Por esta razão, todos os roteiros são publicados junto com as entrevistas ao final do processo.

\section{Realização e produção de entrevistas}

Agendar entrevistas com ministro(a)s do Supremo não é tarefa fácil. A maior dificuldade que o projeto enfrenta, até hoje, é convencer potenciais entrevistados a participar. Isto é feito a partir de cartas-convite e telefonemas, que, algumas vezes, esbarram na barreira dos assessores, assistentes e secretários. Não obstante, a equipe do projeto obteve sucesso em convencer 21 dos 28 entrevistados possíveis, até o momento. Outro obstáculo é a idade avançada de alguns ministros. O ministro Paulo Brossard, por exemplo, infelizmente faleceu alguns meses após conceder sua entrevista. Felizmente para a memória do Supremo e do direito brasileiro, as palavras deste ministro ficarão registradas pelo projeto. O ministro Djaci Falcão, por outro lado, infelizmente faleceu pouco antes do início do projeto.

O maior desafio atual do "História Oral do Supremo" é convencer a primeira mulher a conceder entrevista. Na história do Supremo, apenas três mulheres foram ministras: Ellen Gracie (aposentada), Rosa Weber e Cármen Lúcia (na ativa). Esperase que estas entrevistas forneçam indícios sobre a dinâmica de gênero em ambientes historicamente dominados por homens, como as faculdades de direito, os círculos políticos e jurídicos nacionais e o poder judiciário. A dinâmica de gênero dentro do próprio Supremo ainda é desconhecida, apesar de declarações pontuais das ministras sobre o assunto na imprensa. ${ }^{9}$

As entrevistas foram, em sua maioria, realizadas por Fernando Fontainha e pelos membros das equipes da Direito Rio, Direito SP e CPDOC que elaboraram cada roteiro, em cidades como Brasília, Rio de Janeiro, São Paulo e Porto Alegre. Técnicos do CPDOC ou equipes externas contratadas ficaram encarregados da filmagem e armazenamento dos vídeos. A maioria das entrevistas foi realizada apenas com o entrevistado presente, mas, em casos excepcionais, a pedido do ministro, estiveram presentes também esposas e assessores. As entrevistas são realizadas em uma ou mais sessões, de acordo com a disponibilidade do entrevistado.

Todas as entrevistas começam com a trajetória de vida para chegar ao momento em que a posição no Supremo foi cogitada pela primeira vez, a campanha, nomeação, sabatina, posse, até o cotidiano do tribunal e os casos mais difíceis, seguindo, de maneira não rígida, as perguntas de pesquisa previamente elaboradas. A regra é dar liberdade ao entrevistado. Por exemplo, ao invés de perguntar diretamente sobre determinado caso que o entrevistador entende ser relevante, é mais apropriado

\footnotetext{
${ }_{9}$ O projeto foi encerrado sem que fosse possível entrevistar nenhuma das três mulheres. Talvez seja possível reabri-lo, no futuro, por ocasião das aposentadorias de Carmen Lúcia e Rosa Weber. É comum que pessoas em cargos altos como este prefiram esperar a aposentadoria para participar em projetos de memória institucional. Ainda que não aconteçam dentro do projeto "História Oral do Supremo", as entrevistas com estas ministras poderão fazer parte de projetos de história oral com foco temático, por exemplo, nas dinâmicas de gênero dos círculos das elites político-jurídicas brasileiras.
} 
perguntar ao ministro qual foi o caso que lhe deu mais trabalho ou qual caso considera ter sido o mais importante de sua carreira.

Um dado anedótico sobre a entrevista que realizei, junto com os professores Diego Werneck e Thomaz Junqueira, com o ministro em atividade Dias Toffoli, pode ilustrar este ponto. Ao ser perguntado sobre os casos mais importantes que havia decidido, Toffoli nos apresentou uma longa lista de processos que considerava relevantes. Uma lista como esta poderia dizer algo sobre a percepção do ministro, mas não nos forneceria o tipo de depoimento aprofundado que uma entrevista de História Oral pretende colher. Percebemos, então, que, ao ler sua lista, o ministro mencionou duas vezes a Ação Penal 470, conhecida como "Mensalão". Não havíamos mencionado o "Mensalão" antes por receio de que o entrevistado se sentisse pressionado a falar de um julgamento tão complicado e politicamente carregado, durante o qual havia sofrido inúmeras críticas. No entanto, aproveitando o momento, pedi que o ministro nos falasse um pouco mais sobre sua atuação no caso. Toffoli não hesitou e deixou claro, em detalhes, quanto trabalho aquele caso lhe havia exigido. ${ }^{10}$

Em alguns momentos, o entrevistador-condutor deve intervir para que seja possível tratar de todos, ou quase todos os temas, especialmente quando há escassez de tempo. As perguntas de pesquisa e os roteiros servem de referência caso, por exemplo, o entrevistado não se recorde de determinado acontecimento. Nestes momentos, cabe ao entrevistador entender as escolhas do entrevistado, mas, se as circunstâncias permitirem, lembra-lo do acontecimento sobre o qual se pretende produzir informações. É importante que, a todo o momento, seja mantida uma relação de confiança entre entrevistador e entrevistado. Com ministros e ex-ministros do Supremo, algum grau de deferência no tratamento é apropriado para construir este tipo de relação. No entanto, são as primeiras interações e, muitas vezes, o local da entrevista que determinarão o tom geral da relação. Ministros como Nelson Jobim e Sidney Sanches, por exemplo, mostraram-se descontraídos ao falar de suas trajetórias.

Até o momento, o projeto produziu 93 horas e 35 minutos de entrevistas. As 20 entrevistas finalizadas têm, em média, 4 horas e meia de duração, sendo a maior a do ministro Nelson Jobim, com 9 horas e 46 minutos, e a menor a do ministro Rafael Mayer, com 2 horas e 22 minutos. Optamos por deixar o ministro Edson Fachin, nomeado muito recentemente, em junho de 2015, fora do escopo do projeto.

Para que as entrevistas pudessem ser divulgadas, foi preciso colher a assinatura dos termos de cessão de direitos. Alguns ministros assinaram imediatamente após a entrevista, outros assinaram após revisá-la. Cada entrevista é transcrita por especialistas e, depois, revisada por técnicos e pelo entrevistado. Os pesquisadores responsáveis, então, realizam a conferência de fidelidade e elaboram o índice que servirá de guia para os leitores. Na fase final, caso o entrevistado tenha realizado cortes substanciais, a equipe do CPDOC edita os vídeos, antes de publicá-los online. A equipe de publicações da FGV Direito Rio se encarrega da produção dos livros.

${ }^{10}$ Disponível em: <https://historiaoraldosupremo.fgv.br/entrevistados/dias-toffoli>. 


\section{Difusão interna e externa}

Cada entrevista é publicada como livro individual, com tiragem limitada. Optouse por publicar as entrevistas em caixas contendo 5 livros cada. Até o momento, duas caixas foram publicadas, com os volumes de 1 a 5 (Rafael Mayer, Aldir Passarinho, Sepúlveda Pertence, Cezar Peluso e Sidney Sanches) e de 6 a 10 (Célio Borja, Carlos Velloso, Néri da Silveira, Nelson Jobim e Eros Grau). Os volumes 11 a 15 foram lançados em setembro de 2016, com as entrevistas de Luiz Fux, Luís Roberto Barroso, Moreira Alves, Francisco Rezek e Ilmar Galvão. Em 2017, foram publicadas as entrevistas com Paulo Brossard, Ayres Britto, Teori Zavascki, Octávio Gallotti, Marco Aurélio e Dias Toffoli. No site do projeto, as entrevistas encontram-se tanto em vídeo quanto no formato publicado nos livros. Portanto, seguindo a orientação de livre acesso ao conhecimento da FGV Direito Rio, o projeto disponibiliza todos os seus produtos online, licenciados em Creative Commons. Desta forma, pesquisadores e outros interessados podem acessar o material produzido de qualquer parte do mundo. ${ }^{11}$

Como estratégia de difusão, as entrevistas do projeto têm sido usadas como base para artigos publicados no "Supra - Supremo Interpretado", coluna escrita por professores e pesquisadores da Direito Rio e de outras instituições, publicada no site de notícias jurídicas Jota. ${ }^{12}$ Entre os artigos mais recentes, escrevi sobre o papel do Supremo e de seu presidente no processo de impeachment de Fernando Collor, em 1992, sobre as campanhas realizadas para se chegar ao Supremo e sobre o impacto do novo Código de Processo Civil na prática da declaração de suspeição por ministros do Supremo. ${ }^{13}$ Além dos artigos publicados no Supra, que alcançam público fora dos meios acadêmicos, a FGV Direito Rio promoveu lançamentos das caixas da coleção que contaram com as presenças dos próprios ministros, além de professores, membros do judiciário, advogados e alunos de diversas instituições do Rio de Janeiro.

As estratégias de difusão externa produziram resultados imediatos, levando o projeto a ser citado, inclusive, dentro do próprio Supremo. Na ADPF 378/2016, sobre o rito do processo de impeachment, tanto o parecer do Procurador-Geral da República, Rodrigo Janot, quanto o voto do ministro Luís Roberto Barroso citaram a entrevista de Sidney Sanches, que era presidente do Supremo quando a corte se reuniu pela primeira vez, em sessão administrativa em 1992, para decidir sobre a adequação da Lei n⿳…1079, de 1950, que regula o impeachment, à Constituição de $1988 .{ }^{14}$

11 Todas as 21 entrevistas mencionadas foram concluídas e estão disponíveis em $<$ https://historiaoraldosupremo.fgv.br/>.

12 Disponível em: <http://jota.uol.com.br/tudo-sobre/supra>.

13 Pedro Cantisano, “O impeachment no STF: o olhar dos ministros sobre o caso Collor" (23.07.15); “Campanha para ministro do Supremo?" (23.11.15); "Amizades sob suspeição no Supremo" (24.03.16); e "Um juiz no Senado: memórias de Sidney Sanches no impeachment de Collor" (21.06.16).

14 Supremo Tribunal Federal, Anotações para o voto oral do ministro Luís Roberto Barroso, ADPF 378/2016, p. 18. Disponível em: <http://www.stf.jus.br/arquivo/cms/noticiaNoticiaStf/anexo/ ADPF378LRB.pdf>. Acesso em 22 de jun. 2016. Ministério Público Federal, manifestação do Procurador-Geral da República, ADPF 378/2016, p. 21. Disponível em: 
Internamente, o projeto tem sido utilizado por professores, pesquisadores e alunos da FGV Direito Rio. Professores e pesquisadores interessados no funcionamento do Supremo e no processo decisório dos ministros analisam as entrevistas como dados qualitativos que servem para confirmar intuições e gerar hipóteses, além de fontes que revelam as percepções dos ministros. Na produção acadêmica, é possível integrar as entrevistas do projeto a fontes produzidas em outros projetos. Por exemplo, as percepções dos ministros podem ser contrastadas com resultados quantitativos obtidos através da plataforma "Supremo em Números", também da FGV Direito Rio. ${ }^{15}$ Em sala de aula, as entrevistas têm sido amplamente exploradas na disciplina "Processo Decisório no STF" e podem ser usadas em disciplinas como "Teoria do Direito Constitucional" e "Sociologia Jurídica". Na prática de pesquisa da graduação, os alunos da Direito Rio já aproveitaram o projeto em oficinas de pesquisa e em trabalhos de conclusão de curso. ${ }^{16}$

\section{CONCLUSÃO}

O projeto didático e científico da FGV Direito Rio é comprometido com o ensino e produção de conhecimento sobre o direito para além da análise e elaboração de teses, conceitos e argumentos jurídicos com base em legislação, teoria e jurisprudência. Uma das faces deste projeto é conhecer o funcionamento das instituições que se interpõem entre estas teses, conceitos e argumentos e a realidade política, social e econômica do país. Mais especificamente, o poder judiciário brasileiro e seu órgão superior, o Supremo Tribunal Federal. É conhecendo a realidade constitucional brasileira que os professores e pesquisadores da FGV Direito Rio são capazes de mudar esta mesma realidade. Conhecer o Supremo, portanto, é ferramenta de crítica e aperfeiçoamento daquela instituição. O projeto "História Oral do Supremo" é parte desta agenda. ${ }^{17}$

Utilizar os depoimentos do "História Oral do Supremo" em pesquisas sobre o direito exige alguns cuidados metodológicos. Além das já mencionadas dificuldades em interpretar uma memória produzida em um processo interativo, muito tempo depois de determinados acontecimentos, e em lidar com as seleções e diferentes versões que este tipo de fonte fornece, existem dificuldades peculiares ao projeto.

Por exemplo, ministros podem optar por discorrer sobre aspectos técnico-jurídicos dos casos mais importantes que decidiram, ao invés de revelar as complexas interações

<http://stf.jus.br/portal/processo/verProcessoAndamento.asp?incidente=4899156>. Acesso em 22 de jun. de 2016.

${ }^{15}$ Por exemplo, ARGUELHES, Diego Werneck; HARTMANN, Ivar A. Timing control without docket control: how individual Justices shape the Brazilian Supreme Court's agenda. Journal of Law and Courts, 2017. O Supremo em Números está disponível em http://www.fgv.br/supremoemnumeros/

16 Por exemplo: DA SILVA JÚNIOR, Alexandre Neves. Entre o Direito e a Política: a trajetória do ministro Nelson Jobim. Trabalho de Conclusão de Curso. FGV Direito Rio, 2015 e CID, Alessandra et al. O Supremo por seus Ministros: o impacto da criação da TV Justiça no processo decisório do STF. Projeto de oficina de pesquisa coordenada por Diego Werneck e Leandro Molhano, FGV Direito Rio, 2015.

17 Outros projetos desta linha incluem os já mencionados "Supremo em Números", disponível em http://www.fgv.br/supremoemnumeros/, e "Supra - Supremo Interpretado", disponível em http://jota.uol.com.br/tudo-sobre/supra 
políticas que permeiam a atuação do Supremo. Isto parece ser mais comum entre aqueles que atuaram durante a Ditadura Militar, quando o judiciário se encontrava sob constante pressão do poder executivo, e entre ministros em atividade, que ainda precisam lidar com aquelas interações em seu dia-a-dia. Ministros aposentados, por outro lado, podem construir uma imagem saudosista do Supremo que compuseram, exagerando em suas críticas ao tribunal atual. Em casos como estes, cabe ao pesquisador problematizar a fonte que utiliza, não aceitando como verdade absoluta aquilo que é dito, às vezes de maneira muito convincente, pelos entrevistados. É por isso que precisamos falar em versões, perspectivas ou percepções múltiplas quando interpretamos os depoimentos do projeto.

Não obstante estas dificuldades metodológicas, o "História Oral do Supremo" é uma janela para a realidade do funcionamento da corte mais importante do país. Se a Constituição estabelece critérios e procedimentos para o processo de indicação de ministros do Supremo, o projeto revela como estas normas abstratas funcionaram na tortuosa realidade das trajetórias jurídicas e políticas daqueles que chegaram ao tribunal. Às teses jurídicas que muitas vezes vemos como resultado de argumentos e teorias importadas, universais e lógicas, as memórias dos ministros contrapõem necessidades pragmáticas e negociações de bastidores, entre os próprios ministros e entre eles e políticos e advogados. Ao invés do grande jurista-intelectual, homenageado em coletâneas de livros e em repetidas citações, o projeto revela pessoas com trajetórias de muito sucesso, porém cheias de hesitações e percalços, capazes de agregar enorme capital político a partir de relações interpessoais nos círculos mais exclusivos das elites jurídicas e políticas brasileiras. Contra a imagem de juízes que elaboram as teses que são reproduzidas em manuais e assinam os votos que serão lidos por todo o país, o projeto apresenta administradores hábeis, que tentam tornar mais eficiente o trabalho de um tribunal abarrotado de processos.

Estas são apenas algumas das surpresas que o "História Oral do Supremo" oferece ao leitor. Para além da utilidade acadêmica, as entrevistas proporcionam uma leitura fácil e prazerosa a todos os interessados no funcionamento do Supremo e na história do Brasil em geral. O comprometimento da FGV Direito Rio é, além de influenciar o próprio Supremo, levar o conhecimento produzido sobre a realidade do tribunal a todos. É, nesse sentido, democratizar este conhecimento para que a sociedade brasileira seja capaz de participar ativamente do debate a respeito de um poder que, até pouco tempo, operava nas sombras. 